\title{
Design Research on Mingli Culture Based on Visual Imagery
}

\author{
Jing HU \\ School of Arts and Communications \\ Wuhan Polytechnic University, Wuhan, Hubei, China \\ hj20051118@126.com
}

\begin{abstract}
The essay studied contents and main ideas of the Mingli culture, illuminated opinions of the culture to individuals, fam ilies and societies and their dialectical relations, and urging and guiding effects of its ideas and values on the modern society. The essay analyzed expression forms of the culture from the aspect of visual imagery, extracted the symbols in the culture, and formed the imagery form of integration of words and patterns. Moreover, the essay expressed essences of the culture with simple visual language images to make it carry forward the educating effect of culture, improve individual quality, and promote internal and external cultivation.
\end{abstract}

Keywords-Mingli culture; individual; family; society; visual imagery

\section{INTRODUCTION}

The Mingli culture has a long history and has profound contents. The word "Mingli" first appeared in Han Dynasty. In Discourses on Salt and Iron, Shen Buhai from Han Dynasty, Huan Kuan stated: Mingli and execution are evils to the demon while blessings to the good[1]. From the macroscopic perspective, logos are advocated by the public and they play as the footstone for a stable society. The Chinese nation has experienced ups and downs in the past several thousand years, and there are internal reasons for why it could become a community with a common future. And the main reason is the influence of the Chinese ideologies and culture which have affected thinking habits of Chinese people and cultivated their behaviors and values unconsciously. As time passes, the culture genes with the same roots are cultivated. As an important content of the Chinese culture system, Mingli culture does not belong to a certain ideological school. However, it contains cultural thoughts of Confucianism, Buddhism and Taoism, and it is a traditional culture which has been widely accepted by Chinese people. On the one hand, it reflects the benevolence and courtesy -centered Confucianism and discusses significance, values and essence of human beings; and on the other hand, it includes the Taoism critical thinking, and realizes the care to individuals, worship the nature and improve epistemology of human beings by use of the Taoism dialectical philosophy thoughts[2], and meanwhile, it advocates Buddhism inaction and purify human beings to obtain inner peace by seeking for spiritual consolation. The Mingli culture which is formed according to different understanding angles and thoughts has become standards observed by people for their behaviors, thus it will present rich and precious culture heritages to us after the evolution of hundreds of years.

\section{ANALYSIS OF THE MiNGLI CULTURE ABOUT INDIVIDUAL, FAMILY AND SOCIETY}

Individuals, families and societies have been topics of the human society. The dependence relations among the three contain certain internal rules since they proceed according to certain rules and orders. About this, the culture have distinct explanations and opinions: in the aspect of individual, it involves problems about emotions, culture and life; in the aspect of family, it involves relations among parents, brothers, sisters and elderships; and in the aspect of society, it talks about treatment of careers, friends and partners, which are as shown in TABLE.1.The three talk about problems of human beings in essence, and discuss methods and attitudes to people and matters.

TABLE I. CONTENTS OF THE Mingli CUlture

\begin{tabular}{|c|c|c|c|}
\hline \multirow{2}{*}{ Objects } & \multicolumn{3}{|c|}{ Cultural refinement and moral expression } \\
\hline individual & $\begin{array}{c}\text { Mate } \\
\text { (emotion) }\end{array}$ & $\begin{array}{c}\text { Elegance } \\
\text { (self-cultivation) }\end{array}$ & $\begin{array}{c}\text { Happiness } \\
\text { (life) }\end{array}$ \\
\hline family & $\begin{array}{c}\text { Filiality } \\
\text { (parents) }\end{array}$ & $\begin{array}{c}\text { Family (brothers } \\
\text { and sisters) }\end{array}$ & $\begin{array}{c}\text { Respect } \\
\text { (eldership) }\end{array}$ \\
\hline society & $\begin{array}{c}\text { Promotion } \\
\text { (career) }\end{array}$ & $\begin{array}{c}\text { Harmony } \\
\text { (friends) }\end{array}$ & $\begin{array}{c}\text { Trust } \\
\text { (partners) }\end{array}$ \\
\hline
\end{tabular}

\section{A. Individual}

In the aspect of individual, the Mingli culture can be summarized as mate, elegance and happiness. For emotional problems, it is just as what is said in the Book of Songs: a quiet and modest maiden, a gentleman's good mate. Only under the condition that there is an affiliation between two lovers can they become spouse. It has reflected the pursuit of Taoists for a heaven-made match - good love will not be disturbed or restrained. In the aspect of self-cultivation, it advocates elegance, which refers to promote mental and physical satisfaction, realize spiritual detachment and pursue for the Taoism selflessness with elegant interests. In the aspect of life, it emphasizes perception of happiness. It advocates to enjoy pleasures of life and to recognize truths of life through life. In the aspect of individual, the culture covers social needs, respect needs and self-realization needs in Maslow's hierarchy of needs. It talks about spiritual needs in the middle and high levels directly while neglecting physical and security needs in bottom levels. It reveals the broad and long-term view of the 
culture to problems and it belongs to the philosophy field which explores significance and value of human beings.

\section{B. Family}

The Chinese culture has been titled as "a state of ceremonies". In the aspect of family, it emphasizes family education and family traditions. The Mingli culture has revealed the inclination to humanity of Confucianism which is featured with kindheartedness and justice and it pays attention to harmonious family ties. Morality, the Thirteenth states: to educate filial piety, people in the world will be respected by their children; and to educate love and respect, people will be loved and respected by their brothers [3]. The Confucian culture praises highly of filial piety and fraternal duty so much that it can be seen from its influence on later generations. Filial Obedience, fraternal duty, and sense of propriety, justice and honor are foundations of individuals and families for prosperity. Filiality, family and respect advocated by the Mingli culture are guiding thoughts for settlement of family ties. It advocates to love and respect parents and elderships, and love brothers and sisters. "Be respectful towards one's superiors and kind towards those under him" expresses the same opinion.

\section{Society}

In the aspect of society, it not only involves individuals but also members of the community who has a connection with them. Promotion, harmony and trust have summarized attitudes of the Mingli culture towards social relations. First, promotion reflects internal planning and prospects of careers. According to requirements of the Mingli culture, promotion should conform to moralities. And in other words, it should abide by laws and disciplines, kindheartedness and faiths. It is legal and reasonable to restrict pursuit in career with Taoism, which is a specific reflection of the Chinese traditional social civilization and an ideological basis to support progress and development of Chinese people. In the aspect of managing friendship, the culture emphasizes commonness. Commonness is a precondition of a friendship, and there is harmony when there is commonness. Just as it is said, birds of a feather flock together. Only when they have same cognitive patterns can they become intimate friends. Trust is a priority among priorities when managing partnership. Trust is a basis for success and a precondition to keep a foot in a society. It is a survival and living road that Chinese people should stick to, and it has reflected the basic value of China.

\section{Visual Imagery AND Profound AnAlysis of THE Mingli Culture}

We have mentioned the nine creeds of the Mingli culture above: mate, elegance, happiness, filiality, family, respect, promotion, harmony and trust, which hook on to various behaviors of people in daily life and can be perceived by heart. Then, in visual expression, we can derive visual symbols from culture perception[4], which is shown in Fig. 1 Various symbols alter, set off and complement, thus forming new visual sights. The derivations are based on transformation of visual imagery. As a kind of subconscious subjective thinking activities, individuals should have careful observation and profound understanding to life. They are Artistic conceptions and image associations of objective objects based on cognitive experience. From the viewpoint of expression of contents, visual imagery are combined through images and likeness, and appearance and soul, and to capture various life scenes and contents to turn them into simple forms so as to obtain a strong and vivid contrasting effect and form striking images with profound meanings. To realize the perceptual intuition and richness of implied meanings, pictures take keywords of the Mingli culture as major elements and select from their strokes. On the premise of not affecting basic structures of characters, culture symbols are combined to form visual imagery with pictographic characters and meanings[5]. Here, the characters in the new form seem to be incomplete, but they are favorable supplements to forms and meanings and have avoided opposite relations due to character defects effectively so as to make the sense of form to the ideal state.

\begin{tabular}{c|c|c|c|c|c|c|c|c|}
\hline \multicolumn{3}{|c|}{ Individual } & \multicolumn{3}{c|}{ Family } & \multicolumn{3}{c}{ Society } \\
\hline Mate & Elegance & Happiness & Filiality & Family & Respect & Promotion & Harmony & Trust \\
\hline & & & & & & & & \\
\hline
\end{tabular}

Fig. 1. Transformation of visual imagery of the Mingli culture

\section{A. Mate}

"Mate" is used to express the love affairs between a man and a woman. In the picture, the form of the character "Mate" comes from tai ji diagram of Taoism, and the original image is a round pattern composed of 2 fish pisciform patterns that contain a philosophy that all things in the world transform with each other and integrate. The pattern that made up of up-anddown, forward-and-backward forms evolves into a pattern of fortune that is being loved by people, such as "A Happilymatched Couple" and "Prosperity Brought by the Dragon and the Phoenix". The character "Mate" we see is an abstract pattern, the man referring to the positive, and the woman referring to the negative. They are together and interact with each other. Such a picture that a couple are with each other and show their romantic relationship catch your heart and make you lost in wild and fanciful thoughts.

\section{B. Elegancy}

“Elegancy" is a direct expression of a person's culture. There are many ways to be an elegant person, and the key to it lies on what interests you develop. Erhu, as a traditional musical instrument of long history, is very enjoyable for its sound. So, it matches perfectly with the form of the character Ya, mixing the form and the connotation. The ancient people have a saying - "Sounds of Nature"-to describe a sound that gathers the essence of the heaven, the earth, the sun and the moon. There's another saying - “This song should only exist in the heaven, and people on the earth have few chances to listen.” Brilliant and elegant melodies can always touch our 
heart, making us deeply moved and developing our good temperament.

\section{Happiness}

"Happiness" is a release of mood in one's life, and an expression of the state of life. Its image can be expressed by traditional Chinese auspicious pattern- "Ru Yi" (a traditional Chinese tool and symbol of happiness and auspice). As a lot of things have changed, though $\mathrm{Ru} \mathrm{Yi}$ has already disappeared in people's daily life, it's well known by the young and the old. It carries a historical connotation of happiness and auspice and is still so pleasing to the eye and to our mood, being as an incarnation people love to see and hear. There's a saying " $\mathrm{A}$ pattern must have its own connotation that must be auspicious". It is a specific culture Chinese nation give to the symbols they create. Years passed by, and the symbol continues to be vigorous and becomes the collective consciousness of Chinese nation.

\section{Filiality}

"Filiality" is a traditional Chinese virtue. People always say that "Filial obedience is the foundation of all virtues". The virtue of Filial has a long history. In the character structure of "Filiality", the upper part means the parents, and the lower part means the children. The imagery of "Filiality" is very vivid and lively, educating people silently.

\section{E. Family}

The traditional Fangsheng grain of "Family" is a pattern in which 2 rhombuses lay one atop another, forming a symbol that comes in pairs endowed by people with a beautiful meaning of "Being with each other whole-heartedly and eternally". People use it to express their longing and pursuit to love affairs. At the same time, it also indicates the relationship of a family, or that of brothers and sisters. Fangsheng grain is symmetric, balanced, successive, and simple and intensified in its decoration function. It means equality and caring about each other for brothers and sisters. It integrates with the unique life experiences, emotions, and esthetics of Chinese people, as a display of eastern individuality and characteristic artistic style.

\section{F. Respect}

"Respect” as a culture, has existed in China for thousands of years. As a state of courtesy, "being modest and polite" has grown like a tree in the national character of Chinese people. Being respect in front of an elder people is not merely a gesture, and it doesn't mean that a person is not proud or arrogant for his/her wealth of knowledge, nor is he/her inflated with pride for an enjoying high social state. On the contrary, it is a high level of manifestation of a person's inner morality and education.

\section{G. Promotion}

"Promotion" is a dream a person endeavors for in his/her mind. The doctrine to be promoted lies not in playing politics and power tactics, but in personal struggle and talents and others' acceptance. A bamboo just rightly expresses the way to be promoted. The bamboo has long been loved by men of literature and writing. It's been loved not only owing to its external beauty for its growing with rhythm, but also due to its cultural connotation for being pliable and open-minded that is highly praised by people.

\section{H. Harmony}

It's said by people that "Harmony is precious". During the interaction of friends, "He" is the foundation of their smooth relationship. It combines the advantages of two people and improves the shortages mutually, but doesn't assimilate them. In this way, it forms a perfect life status. The good story of Bo Ya and Zhong Ziqi has been long praised for tens of hundreds of years. There's poem saying: "I smashed the Guqin and it went cold on earth. Since Ziqi was gone, who would I play Guqin to? The world is big, and people are my good friends. But it's too hard to meet a bosom friend.” Good people or things have to be together in pairs, and then such a beauty comes along. "A perfect pair of pearls and jade” just accounts for the principle.

\section{Trust}

"To be honest and trustworthy" is of key importance in human beings' production and living. It is the foundation to be a person, to start up one's vocation, to prosper a country and to develop human beings. It can even decide a person's social status and social stability. People always say "A word can carry thousands tons of weight”. The word has been passed down to generations and generations who learn it and take it as their faith.

Effect of the visual imagery of the Mingli culture is an invisible interactive process. Images which are constructed on the basis of observed objects by the originator may have subjective factors and cannot be accepted by audiences. However, audiences will have more visions ad form their own ideas when inspired by potential visual language stimulus contained in visual imagery. The thinking process is a process which is inspired and affected by the Mingli culture, and the impelling effects are invisible, profound, and meaningful. It is noteworthy that cultural spreading is not an education imposed on human beings but an unconscious influence. It tries to mobilize various positive factors to attract more attention and explorations to the Mingli culture by exploring more creative thoughts from various view angles. Innovations of visual imagery of the Mingli culture are injected with more novel ideas and energy by audiences so as to stimulate potentials and possibilities to discuss the Mingli culture. Thus, the originator and viewers are not isolated, instead, they work together to finish the cultural inheritance.

\section{SUMMARY}

The Mingli culture is broad and profound, but it has not been fully developed yet by now. Problems like how to use accurate and proper visual language to realize imagery interpretation and how to manifest humanistic spirits of the Mingli culture in a more profound way should be further studied. 


\section{REFERENCES}

[1] [Han] Huan Kuan, Bai Zhaolin (translated).Notes for Discourses on Salt and Iron [M]. Hefei: Anhui university press, 2016.6

[2] Hong Xiuping. Ideologists of Confucianism, Buddhism and Taoism and Ideologies and culture of China [J].Jiangsu Social Sciences (study of philosophy),2007 (6):9-14.

[3] Xu Yanping (translated).The Classic of Filial Piety [M].Beijing: Beijing joint publishing company, 2015.7
[4] Zheng Jun. Chinese auspicious pattern design series [M].Beijing: People's Fine Arts Publishing House, 2013.3

[5] Yin Xia. Reflection on design theories of traditional visual images for the Spring Festival - taking the "happy Spring Festival" visual identification system of Central Academy of Fine Arts as an example [J].Art and Design (theory), 2016 (6): 51-53. 